\title{
Construcción de una Gobernanza Local en Red: El Caso de la Remurpe en el Perú
}

Edgar Quispe Mamani

Perú

Fecha recepción: 08/01/2012

Fecha aceptación: 26/03/2012

\section{Resumen}

El artículo se centra en el análisis de la experiencia de gestión organizativa de la Red de Municipalidades Urbanas y Rurales del Perú (REMURPE), dando cuenta de su origen, dinámica y racionalidad organizativa, toma de decisiones, acciones y relaciones de poder al interior y al exterior, y la dinámica de configuración de las Redes de Cooperación Intermunicipal (REDCIM). El desarrollo de esta experiencia dio lugar a la construcción de un modelo de gobernanza local en red, complementario/alternativo al modelo de gobierno basado en la jerarquía estatal.

Palabras clave: Gobiernos locales - Redes de cooperación intermunicipal Gobernanza local.

\section{Construction of a Local Governance in Net:The Case of Remupre in Peru}

\section{Abstract}

The article itself center on the analysis of organizational management experience of the Rural and Urban Municipalities Network of Peru (REMURPE), realizing its origin, dynamic and organizational rationality, decision making, actions and power relationships to the interior and outside, and dynamics of configuration of the Intermunicipal Cooperation Networks (REDCIM). The development of this experience gave rise to the construction of a local governance network model, complementary/alternative to the government model based on the state hierarchy.

Key words: Local governments - Intermunicipal cooperation networks - Local governance 


\section{Construção de uma Governança Local em Rede: $O$ caso da Remurpe no Peru}

Resumo

Este artigo se centra na análise da experiência de gestão organizativa da Red de Municipalidades Urbanas y RuralesdelPerú(REMURPE), levando em conta sua origem, dinâmica e racionalidade organizativa, tomada de decisões, ações e relações de poder no interior e exterior, além da dinâmica de configuração das Redes de Cooperación Intermunicipal (REDCIM). O desenvolvimento desta experiência permitiua construção de um modelo de governança local em rede, complementar/alternativo ao modelo de governo baseado na hierarquia estatal.

Palavras-chaves: Governos locais - Redes de cooperação intermunicipal Governança local - Trabalho em rede.

\section{INTRODUCCIÓN}

El artículo constituye parte de los resultados de la investigación posdoctoral que realiza el autor desde noviembre de 2010 y culmina en marzo de 2012, a través de la Universidad Nacional de San Martín y con el patrocinio del Consejo Nacional de Investigaciones Científicas y Técnicas de Argentina, cuyo propósito es analizar la experiencia de la REMURPE como una propuesta de solución a la problemática del inframunicipalismo, la fragmentación territorial y geopolítica, y la escasa o nula capacidad técnica y política de los gobiernos locales para solucionar problemas sociales e implementar políticas públicas; todo ello como consecuencia de la relación vertical y jerárquica entre Estado y sociedad. La experiencia de REMURPE se analizar, primero, por su cobertura de un número representativo de Municipalidades a nivel nacional, y segundo, por su propuesta de un modelo de gobernanza local en red desarrollada durante los últimos diez años en el país.

La investigación se basa en el método cualitativo/constructivista centrado en el análisis de los actores y sus relaciones al interior y al exterior de la Red, para ello se ha aplicado cuatro técnicas: entrevistas de profundidad diferenciadas a directivos, ejecutivos y asociados de la Red, y a representantes de instituciones públicas y privadas implicadas en las acciones de la Red. Revisión/registro de información documental: publicaciones, informes, memorias, estadísticas y otros documentos. Observación participante de algunos eventos de la Red.Y análisis del discurso, centrado en la interpretación del discurso de los entrevistados.Ahora bien, para el análisis de la información resultante, la investigación se sostiene de manera complementaria en cuatro enfoques teóricos formulados desde diversas disciplinas académicas, a saber: Análisis de Redes Sociales,Análisis de Redes de Políticas Públicas, Gobernanza Local, y Conflicto Social. 


\section{ORIGEN DE LA REMURPE}

Recientemente, ha incorporado a los gobiernos locales urbanos como parte de su estrategia organizativa, por lo que se denomina Red de Municipalidades Urbanas y Rurales del Perú; sin embargo, la Red nace en enero de 2000 principalmente como un gremio representativo de experiencias e intereses de las Municipalidades Rurales del país. Así, la REMURPE ${ }^{57}$ habría tenido su origen como producto de tres fenómenos sociopolíticos muy importantes que se desarrollaron con mayor intensidad durante la década del noventa: primero, el recambio de las elites locales; segundo, la crisis política de la izquierda y del propio sistema de partidos; y tercero, la cooptación política de la AMPE por parte del fujimorismo ${ }^{58}$. Estos fenómenos sociopolíticos se han desarrollado en el contexto de democratización del país, que se había reiniciado desde la década del ochenta.

El recambio de las elites locales se habría iniciado oficialmente y de manera progresiva a partir de la introducción del sistema electoral municipal en 1963, en el país. Por ello, según Degregori, Coronel y Del Pino citado por Remy (2005), en 1966 si bien se mantenían vigentes aún las tradicionales instituciones del sistema de "administración étnica", el cabildo -reunión de vecinos varones de los pueblos- y los varas -autoridades indígenas que median entre las autoridades mistis y los campesinos quechuas-, el sistema se estaba ya desmoronando y nuevos actores empezaban a aparecer y con ello se iniciaba un proceso de recambio en las elites locales: en varios distritos, gracias a las elecciones, no eran hacendados o sus "cercanos", quienes accedían al poder, sino nuevos sectores comerciantes y profesionales. Este proceso se profundiza durante el gobierno militar, con los nuevos alcaldes designados -ya no electos-, entre ellos se encuentran alcaldes de origen indígena, urbanizados; muchos son inmigrantes de retorno con experiencia dirigencial. Pero ya no se encuentran en el escenario municipal, a los varayocs.

Con la restauración democrática y la convocatoria a elecciones municipales en 1980, el camino abierto por el gobierno militar se continúa: los electos son nuevamente campesinos escolarizados con experiencia de migración y/o dirigencia social. Esta tendencia se habría expandido significativamente durante los años noventa. De ahí que diversos investigadores llegan a la conclusión de que en diferentes lugares del país acceden al poder local nuevos sectores sociales. "Grupos emergentes" (Diez, 1999); un "sector comunero económicamente más alto y con más experiencia" (Guerrero, 2002) accede a gobiernos locales en espacios de alta ruralidad desde las elecciones de 1980; “"campesinos emergentes” (Quispe, 2003).

Los hallazgos identificados por este último autor es concluyente en una

57 En adelante éste acrónimo y el término Red se harán uso de manera indistinta.

58 La década del noventa ha sido para el Perú un periodo de desintegración socio-institucional, y por consiguiente la supresión de todo tipo de asociativismo. Como muestra es que la AMPE fue cooptada por el fujimorismo, con el fin de desmembrar el asociativismo municipal y hacer uso de ella. 
investigación realizada sobre el proceso participativo en los distritos de la Provincia de Moho,Provincia aymara en el departamento de Puno.Según él,si bien las relaciones de poder continúan configurándose entre "mistis y campesinos emergentes", sin embargo, "quienes controlan los poderes locales ya no son los mistis, sino los campesinos emergentes". Los mistis o sus herederos desempeñan principalmente cargos en el magisterio - profesores-, quienes en el pasado continuamente tenían el control del poder político local, desde los espacios distritales. Por su parte, los campesinos emergentes, actualmente desempeñan cargos similares al de los mistis y a su vez controlan los poderes políticos locales. Una de las estrategias de ascenso social y político fue la "educación", a través de ella los campesinos emergentes realizan y participan en acciones similares e incluso superiores al de los mistis.

Por tanto, sostenemos que el origen de la REMURPE se da como producto de este proceso de recambio de las elites locales. Porque, quienes inicialmente idearon y constituyeron la Red son, precisamente, alcaldes rurales con características o con perfil nuevo expuesto más arriba.

La conformación de la red de municipalidades rurales del Perú se inicia entre los años 1997 y 1998 ante el incremento de nuevos gobiernos locales liderados por campesinos (REMURPE).

Antes los alcaldes eran gente de los llamados llajtataitas o de los grupos y poderes locales, ahora con mucha facilidad podemos encontrar alcaldes indígenas, quechuas, aymaras, que representan los verdaderos intereses de la población y no de la persona que cree que la municipalidad es un botín, sino también un espacio democrático de gobierno para todos (Wilbert Rozas Beltrán, Ex-presidente y fundador de la REMURPE).

Íntimamente relacionado con lo anterior es la crisis política de la izquierda y la crisis del propio sistema de partidos. Porque desde los años noventa se opera un cambio importante en la configuración de los sistemas políticos locales. Es decir, conforme los partidos políticos desaparecen de las contiendas electorales y dominan los independientes, un rasgo nuevo y decisivo se suma a los anteriores: ser profesional. En este sentido, Degregori, Coronel y Del Pino citado por Remy (2005), sostienen que solamente uno de diez alcaldes pertenece a un partido político, tres de los diez alcaldes tienen título universitario y tres tienen estudios superiores. Asimismo, desde 1990 el número de organizaciones políticas locales compitiendo en las elecciones municipales se ha multiplicado por el creciente debilitamiento del sistema de partidos políticos.

De otra parte, según Quispe (2003), si bien se mantiene la simpatía hacia los partidos políticos tradicionales, sin embargo, la proliferación de movimientos políticos independientes marca su predominio en la configuración de los sistemas políticos locales, lo cual indica en cierto modo la crisis y desaparición de los partidos políticos tradicionales y la configuración de nuevas propuestas de organización política. Así, los partidos de izquierda también han perdido organicidad, espacio y 
legitimidad política a partir de la década del noventa, a pesar de que previamente, alcaldes de izquierda provenientes de gremios campesinos, habían generado experiencias de gestión participativa de referencia en diferentes ámbitos locales ${ }^{59}$, son los casos de Limatambo en Cusco, Santa Rosa en Puno, Castrovirreyna en Huancavelica, Morropón y Santo Domingo en Piura, Sihuas en Ancash, entre otros.

En términos de Remy (2005), a inicios de la década del noventa, cuando las experiencias de participación y concertación surgidas de alcaldes originalmente de Izquierda Unida se expanden a nivel municipal, sin embargo, Izquierda Unida como organización política estaba desapareciendo del escenario electoral. En las elecciones de la década de 1990, son alcaldes de izquierda, pero en movimientos independientes, sin articulación entre ellos, quienes siguen desarrollando y multiplicando estas experiencias de participación y concertación y, sobre todo, formalizándolas en normas y reglamentos.

Entonces, los alcaldes rurales de izquierda provenientes de gremios campesinos de nivel nacional -electos a través de movimientos políticos independientes-, al no contar con un espacio político orgánico a través del cual articular sus experiencias de gestión política local y reivindicar los derechos e intereses de los gobiernos locales rurales, a los cuales representaban, han decidido constituir un espacio orgánico e institucional que se plasmó en la REMURPE.

La Confederación Campesina del Perú CCP y los alcaldes rurales queríamos tener nuestro origen gremial en la CCP y también nuestra orientación política institucional desde la CCP, decidimos formar la REMURPE, y como teníamos origen en la CCP, de ahí que nuestra primera sede se instala en una oficina prestada que nos da la CCP en la plaza Bolognesi (Wilbert Rozas Beltrán, Ex-presidente y fundador de la REMURPE).

Finalmente, y no aislado de los fenómenos sociopolíticos antes expuestos, el nacimiento de la REMURPE se origina como producto del interés inicial de sus impulsores y fundadores por articularse o constituir un movimiento asociativo de representación municipal como parte del proceso de democratización en el país, tal es así que los diferentes alcaldes rurales que fundaron la REMURPE, previamente, formaron parte de la Asociación de Municipalidades del Perú (AMPE), cuya participación implicaba adaptarse a la dinámica organizativa preestablecida. Dicha dinámica contemplaba la conformación de las asociaciones regionales de municipalidades, proceso en el que se habrían generado conflictos de poder e intereses de los actores participantes.

59 Una de las razones centrales para la constitución de la REMURPE ha sido la articulación e intercambio de experiencias exitosas de gestión participativa local. 


\begin{abstract}
"Una etapa tiene que ver con el inicio, que es buscar una representación municipal, que está muy ligado a los procesos de democratización de los años 80, eso logra tener sentido cuando se llega a tener una asociación nacional, este te pone como una de las tantas tareas tratar de construir asociaciones regionales, pero entramos en una etapa de crisis por la desorganización y luchas internas que terminan en el cierre de lo que fue la experiencia magnifica que tuvo...." (Eduardo Barzola, Secretario Técnico de REMURPE) ${ }^{60}$
\end{abstract}

Es más, en el período de gobierno de Fujimori -años noventa-, se da un proceso de fragmentación del movimiento asociativo. Así, según Claros (2009), a partir de enero de 1999 la AMPE entró en un franco proceso de descomposición, cuando el Consejo Directivo fue copado por el movimiento pro-gobiernista al convocar a un congreso eleccionario usurpando las competencias del entonces presidente de la AMPE y marginando de la convocatoria a los alcaldes opuestos al régimen. De esta manera, la dirigencia de la AMPE perdió su legitimidad y su espacio político.Ante esta situación es que los alcaldes rurales crearon la REMURPE como un ente alternativo con el fin de articular a los gobiernos locales rurales y las experiencias de asociativismo y cooperación intermunicipal bajo una propuesta programática dirigida a las municipalidades más pobres y alejadas del país.

Bueno, la REMURPE tiene su origen en que la AMPE, que representaba todo el municipalismo nacional se fue convirtiendo en un brazo político de la dictadura de Fujimori, y esta entidad, en lugar de representar a los alcaldes representaba políticamente a quienes estaban a favor de Fujimori, por entonces yo era alcalde de la Municipalidad de Limatambo, y en ese momento planteamos a la AMPE que debería existir una secretaria que viera asuntos rurales, en el congreso de Cajamarca (1997) se acuerda tener una secretaria de asuntos rurales, he sido miembro de esa comisión, y de ahí nos aglutinamos alrededor de aquella secretaria y ayudada por todos los que éramos miembros de la CCP, para crear la REMURPE (Wilbert Rozas Beltrán, Ex-presidente y fundador de la REMURPE).

Ahora bien, a las tres razones o motivaciones programáticas, identificadas por Salcedo (2008), que dieron origen a la REMURPE -nuclear y promover experiencias novedosas de gestión municipal rural, ser modelos de gestión gobernando junto con la población y ser más transparentes, y aprender y replicar experiencias de cooperación-, es necesario agregar otra que ha sido el motor inicial, se trata de la "representación municipal y la incidencia política" en sus diversas dimensiones y a diferentes niveles. 
En todo este proceso inicial de constitución y configuración de la REMURPE podemos identificar tres tipos de actores: primero, quienes constituyeron la Red fueron las Municipalidades distritales de Santo Domingo,Sicchez y Vichayal,y Provincia de Ayabaca, en Piura; Municipalidad Distrital de Jarpa en Junín; Municipalidades Distritales de Uchiza y Tabalosos, en San Martín; Municipalidad Distrital de San Francisco en Cerro de Pasco; Municipalidad Distrital de Limatambo y Municipalidad Provincial de Espinar en Cusco; y Municipalidad Provincial de Castrovirreyna en Huancavelica. ${ }^{61}$ Segundo, los gremios campesinos que participaron y apoyaron directamente en el proceso de constitución de la REMURPE son los siguientes: Confederación Campesina del Perú (CCP) y Confederación Nacional Agraria (CNA). Tercero, entre las ONG podemos mencionar la participación activa del Grupo Propuesta Ciudadana, GRADE, CEPES, Red Perú y otras ONG regionales.

\section{ESTRUCTURA ORGANIZATIVA: ${ }^{22}$ COMPLEMENTARIEDAD ENTRE LAS DIMENSIONES POLÍTICAYTÉCNICA}

REMURPE asocia a Municipalidades distritales y provinciales de 19 regiones del Perú, asociaciones de municipalidades por cuenca, corredores económicos u otro tipo de asociaciones de continuidad territorial, y redes regionales similares a REMURPE. En este sentido, aunque no se dispone de información precisa en torno a la cobertura del número de municipalidades asociadas a la Red, aproximadamente estaría cubriendo alrededor de 700 municipalidades (38,2\% respecto del total de municipalidades del país) que participan de la Red, ya sea individualmente o a través de asociaciones o redes regionales.

Entonces, la REMURPE como una organización nacional representativa de las municipalidades es dirigida por los propios alcaldes, quienes representan de manera legítima a las municipalidades que son asociadas a la Red. Y de acuerdo con su estatuto institucional, la estructura orgánica está constituida por/en tres niveles: nacional, macroregional y regional. La Asamblea Nacional Anual, es el órgano rector de REMURPE que deposita en la Junta Directiva Nacional la Ejecución de políticas, estrategias y acciones que REMURPE acuerda y realiza anualmente. $L a$ Junta Directiva Nacional, conjuntamente con el Coordinador Nacional, es elegida por la Asamblea Nacional Anual, y asigna al Coordinador Nacional la ejecución del Plan Operativo Anual, quien a su vez es apoyado por la Secretaría Técnica Nacional, ubicada en la oficina de enlace en Lima. La Secretaria Técnica Nacional, es la encargada de gestionar y materializar las políticas institucionales aprobadas por la Asamblea Nacional, la Junta Directiva y el Coordinador Nacional, descritas en un Plan Operativo Anual.

61 www.remurpe.org.pe Fecha de consulta: 17/08/2011.

62 Con base en REMURPE, 2007b. 
Gráfico I: Organigrama estructural de la REMURPE Consejo Consultivo

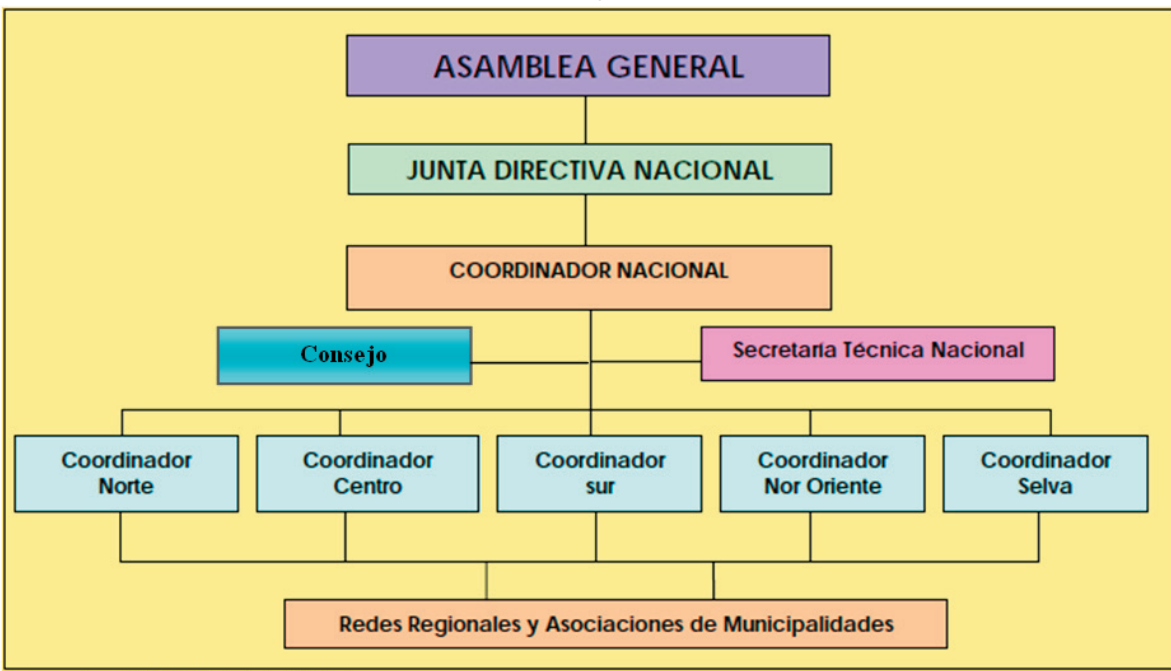

Fuente: REMURPE, 2007.

Gráfico 2: Organigrama funcional de la secretaría técnica de la REMURPE

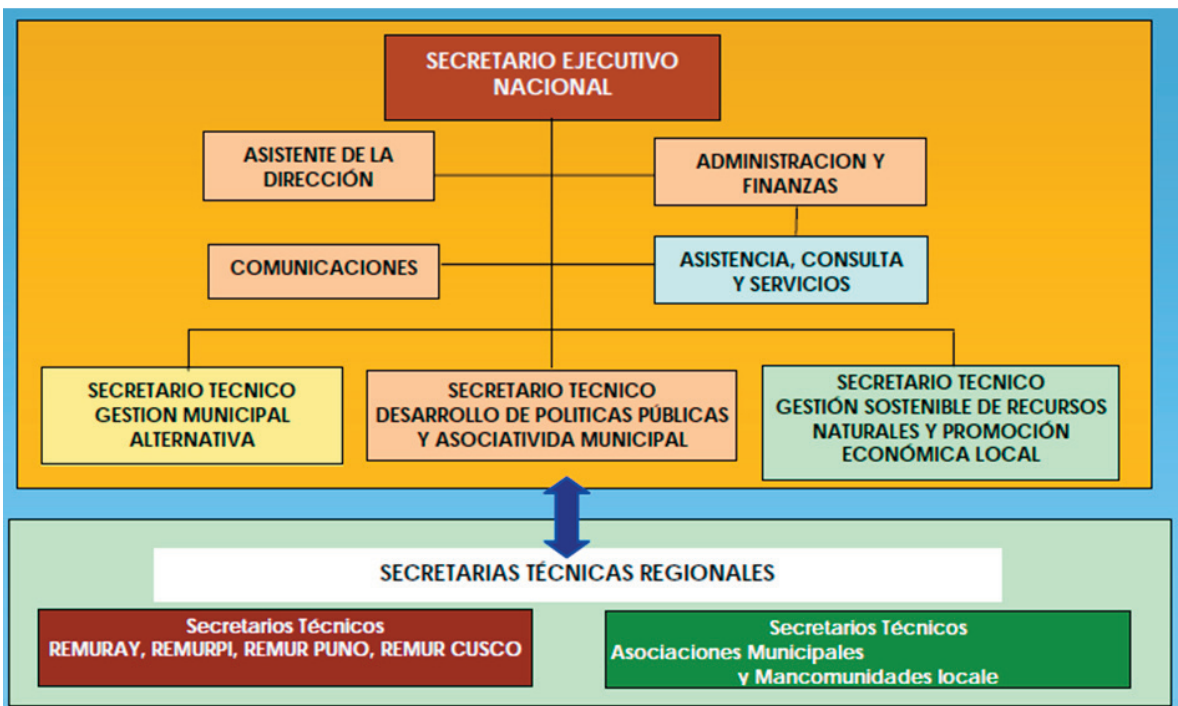

Fuente: REMURPE, 2007. 
Finalmente, en la actualidad se cuenta con cinco coordinaciones macroregionales, así como redes y asociaciones municipales regionales, que a su vez cuentan con sus respectivas secretarías técnicas regionales. Las coordinaciones regionales del norte, centro, sur, nororiente y selva coordinan la organización macroregional, que son reforzadas por las juntas directivas de las Redes Regionales, Asociaciones y Mancomunidades Municipales.

\section{Gráfico 3: Estructura asociativa de la REMURPE}

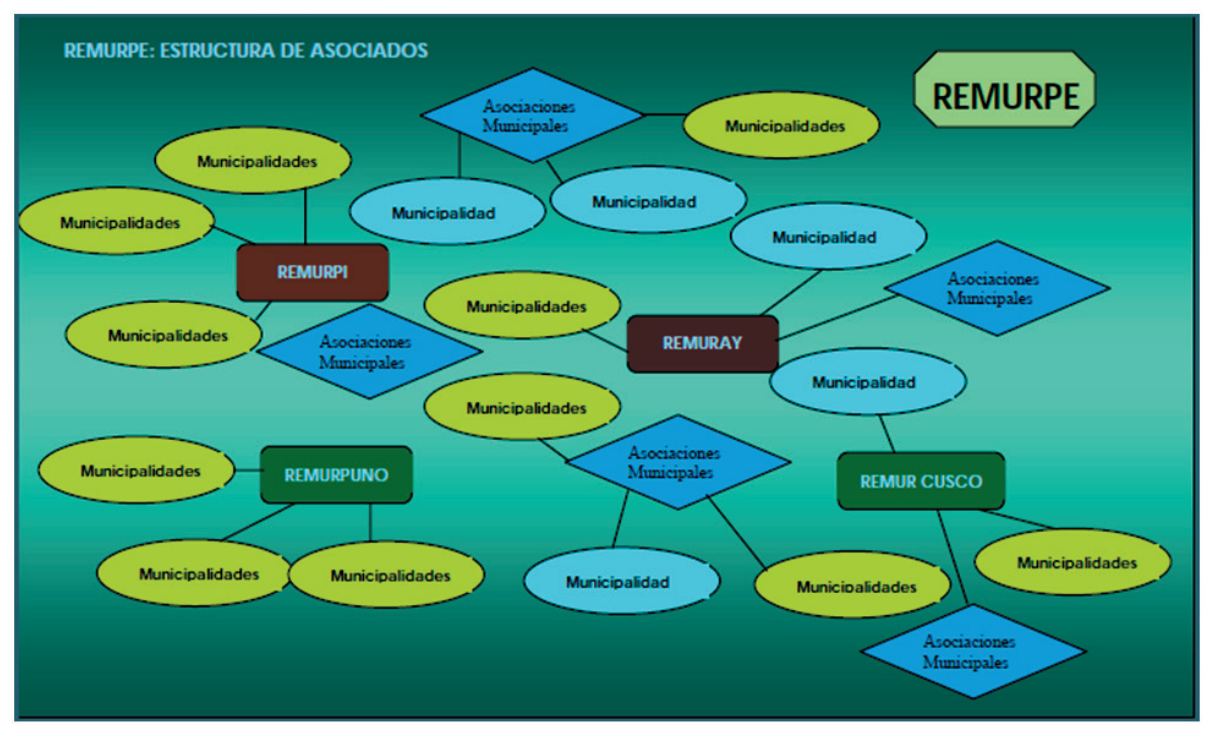

Fuente: REMURPE, 2007.

Desde una perspectiva formal, la estructura organizativa de la REMURPE se basa en un modelo vertical y flexible, y su lógica de funcionamiento responde al enfoque de gestión en red, enfoque de gestión organizacional que la hace relativamente flexible y horizontal en su accionar diario, decimos relativamente porque su diseño formal que da cuenta de una estructura vertical y flexible en las relaciones y toma de decisiones, da lugar a que éstos procesos tengan una tendencia a la centralización y jerarquización. Porque, en buena medida, las decisiones y acciones en las redes regionales dependen, precisamente, de las decisiones tomadas a nivel nacional; salvo algunas decisiones y acciones desarrolladas por redes regionales que funcionan independientemente (con personería jurídica propia) respecto de las acciones de la REMURPE nacional. Con todo ello, estaría reproduciendo, en cierta medida, la tradición centralista de la lógica de funcionamiento del Estado peruano, ya sea por la concentración del aparato administrativo en Lima, o por la concentración y control de recursos de la Red en la oficina de enlace en Lima: información, fuentes y fondos de financiamiento, decisiones, $y$ otros, o por la cultura de dependencia de los actores locales respecto del nivel nacional. 
La red significa articularse entre municipalidades que estamos haciendo gestiones interesantes, este es el fondo del asunto de la denominación...... Hay como 3 o 4 tipos de articulaciones en red, el nuestro es como la telaraña, donde el punto de enlace es aquí, no es que seamos centralistas porque está en Lima, porque por acá están los ministerios, casi todo está por acá, claro como respondiendo al centralismo, al final las decisiones se toman con las regiones (Yolanda Collatón, Secretaria Técnica del área DEL de la REMURPE).

Nosotros somos parte de la REMURPE nacional, aún la red de Puno estamos en proceso de constituirla oficialmente ante registros públicos, ya tuvimos una primera asamblea, ya tenemos nuestros estatutos, estamos esperando la revisión, porque tenemos que revisarlo tanto aquí los alcaldes como también Lima, porque nosotros venimos como dice el Ingeniero Lucho: nuestro padre o nuestros padres van a ser la REMURPE... (Lourdes Betancur, Secretaria Técnica de la REMURPE Puno).

No obstante lo anterior, una de las particularidades y potencialidades replicables de la REMURPE es que a nivel de la gestión organizativa e institucional cuenta con una claridad en la distinción de las funciones y competencias entre los actores participantes e integrantes, tanto en términos de administración y gestión técnica como en la dirección y liderazgo político. Esta claridad se produce en la medida que cuenta con una estructura organizativa a nivel de dirección y liderazgo político y otra estructura funcional referida a la secretaría técnica dedicada exclusivamente a la administración y gestión operativa y técnica de la organización.

Este modelo de gestión organizativa es desarrollado gracias a la flexibilidad y dinamismo que le permite su estatus jurídico privado, ya que como tal, para su funcionamiento no está rígidamente sometido al cumplimiento de los procedimientos legales y administrativos/burocráticos emanados por el Estado para una entidad pública, condiciones a las que sí están sometidas el funcionamiento de las Mancomunidades Municipales. Aunque para su reconocimiento, participación e incidencia en diversos espacios de gestión de políticas públicas ha tenido que amoldarse o adecuarse formalmente de acuerdo con algunos procedimientos del código civil, relacionados con el aspecto organizativo, no obstante ello, no ha cambiado en su práctica organizativa la distinción y la complementariedad entre la dimensión política y la dimensión técnica, lógica que es replicada en los subniveles de organización de la Red.

Inicialmente teníamos coordinadores, como era una red no había una estructura clásica como lo manda el código civil: presidente, vicepresidente y vocal,sino era un coordinador central y coordinadores regionales. 
Hemos tenido un primer cambio estatutario, ahora ya tenemos una junta directiva más tradicional según señala el código civil, porque cuando ya hemos ido teniendo mayor importancia en el país nos han convocado a diversos espacios, y en esos espacios siempre nos cuestionaban...

Nuestra junta directiva ahora es temática aparte de presidente, vicepresidente ahora tenemos un secretario de temas ambientales, secretario de educación, etc. Tienes que hacer eso y a nivel administrativo mantener la estructura básica, y lo otro en el escenario más regional no está prohibido articular asociaciones y mancomunidades, hemos promovido muchas mancomunidades $y$ tenemos relación con un montón de mancomunidades.

El estatus jurídico es privado, la ley tampoco nos permite otra forma de organizarnos, salvo la mancomunidad es la única organización que se ha peleado para que tenga el estatuto de organismo público, pero la REMURPE sigue siendo una forma privada y voluntaria.

(Eduardo Barzola Farfán, Secretario Ejecutivo Nacional de la REMURPE)

Lo importante fue entender qué papel nos tocaba jugar, nosotros los alcaldes jugábamos el papel de determinar la política institucional y el área técnica era para determinar los aspectos de carácter técnico, que no solamente estaba la gente técnica contratada por la REMURPE, sino también en permanente consulta, para eso tenemos un órgano consultivo, en el cual estaban instituciones del Estado y ONG (Wilbert Rozas Beltrán, Ex-presidente y fundador de la REMURPE).

... yo puedo ser responsable del desarrollo económico pero no puedo sentarme en mi cargo de técnico a discutir propuestas con el ministro, para eso está el alcalde, mi directivo, yo le puedo asesorar, incluso darle el papel, escribirle para que conozca a mas detalle de lo que va a proponer, pero quien tiene que pensar la propuesta es el directivo, es el alcalde, entonces ellos son los que se sientan con los ministros, con los congresistas para incidir (Yolanda Collatón, Secretaria Técnica del área DEL de la REMURPE). 


\section{4. ÁREAS ESTRATÉGICAS DE ACCIÓN INSTITUCIONAL}

Las acciones institucionales de la REMURPE están enmarcadas en tres grandes áreas estratégicas: desarrollo de políticas públicas y asociatividad municipal,fortalecimiento de la capacidad de gestión institucional de los gobiernos locales, y gestión sostenible de recursos naturales y promoción del desarrollo económico local. Estas áreas de acción institucional dan cuenta de la implementación de un modelo de gobernanza local en red, porque las diferentes acciones emprendidas en las tres áreas de trabajo implican la configuración o el establecimiento de sistemas de interacción entre actores de diferentes niveles de gobierno en el proceso de su gestión, para su viabilidad se contempla además cuatro ejes transversales de acción: desarrollo de capacidades, incidencia política, comunicación y enfoque de género.

El desarrollo de políticas públicas y asociatividad municipal, entendido como la promoción, incidencia e implementación de políticas desde los ámbitos locales, y la innovación y construcción de instrumentos de gestión local, es un área orientado a la integración territorial de los ámbitos locales gobernados y gestionados a través de municipios de menor escala, y la participación organizada de las municipalidades en el proceso de descentralización y regionalización del país. La idea central que sostiene a esta área de acción es que, además de otras iniciativas, la gestión del proceso de políticas públicas es viable a través de la construcción del asociativismo y la cooperación intermunicipal como un mecanismo de innovación en la gestión pública local.

La REMURPI ayudó a formar muchas mancomunidades como la mancomunidad del Alto Piura, del Andino Central y otras, hay un apoyo técnico, somos conscientes de las limitaciones presupuestales también, pero si no hubiera sido por REMURPE no hubiéramos avanzado lo que hemos avanzado, nos falta mucho por hacer pero por algo se comienza, hay un apoyo muy sincero, muy realista y hay incidencia política (Nelson Mío, Alcalde del Distrito de Matanza y Presidente de la Mancomunidad Municipal Vicus, Piura).

El accionar nuestro es que las municipalidades empiecen a comprender sobre la importancia de las asociaciones, de las redes de municipalidades, porque unidas se puede conseguir más que individualmente (Cesar Vigo, Secretario Técnico REMURCA, Cajamarca)

El fortalecimiento de la capacidad de gestión institucional de los gobiernos locales, entendido como el proceso mediante el cual se desarrollan las habilidades y potencialidades de los actores y agentes locales para el proceso de gestión de las políticas públicas en sus ámbitos, este proceso se implementa a través de un programa de desarrollo de capacidades que consiste en la ejecución de acciones de información y formación, basados en el sistema de inter-aprendizaje: cursos y talleres de capacitación, encuentros e intercambios de experiencias, conferencias, seminarios, 
diplomados y otros, que se realizan ya sea de manera presencial o virtualmente. Este programa de información y formación de la REMURPE se desarrolla como respuesta a un vacío de políticas del Estado orientado al fortalecimiento de capacidades técnicas de gestión hacia los subniveles de gobierno.

No solo era importante pedir, sino plantear, no solo era un problema de salir a las calles y protestar, sino también saber cuál era nuestro carácter de proposición como REMURPE, entonces ahí planteamos tener espacios de desarrollo de capacidades, y no solo de capacidades de autoridades municipales sino también de técnicos institucionales y de la propia población, de ahí que nacieron tres sistemas. Uno es el municipio-escuela que tiene para todo nivel; el segundo, son los diplomados y especializaciones que están dirigidos a autoridades y funcionarios municipales, $y$ el otro que es la conferencia anual de municipalidades rurales que tiene un espacio más grande (Wilbert Rozas Beltrán, Ex-presidente y fundador de la REMURPE).

Nosotros desarrollamos capacidades para que las municipalidades nuestras mejoren su gestión y mejoren sus capacidades de propuesta e incidencia política (Yolanda Collatón, Secretaria Técnica del área DEL de la REMURPE).

Las actividades de REMURPE tiene que ver con el fortalecimiento de capacidades, orientados a género, tener el espacio de regidoras, constituirlas y darles charlas de capacitación y talleres, igualmente para los regidores, $y$ los alcaldes participamos en eventos nacionales y nos actualiza en las propuestas que tenemos que hacer (Luís Butrón Castillo,Alcalde de la Provincia de Puno y presidente de la REMURPE Puno).

La puesta en marcha de todas estas acciones de información y formación han contribuido significativamente en el mejor desempeño de aquellos actores y agentes locales en el proceso de gestión de las políticas públicas locales - aunque para algunos la REMURPE haya sido considerada como un ente filantrópico ${ }^{-}$, en todo caso ha significado un aporte muy importante para los gobiernos locales en el proceso de descentralización que se va dando de manera paulatina en el país.Así, en la medida que los gobiernos locales, ya sea individual o asociativamente, posean las habilidades y competencias necesarias para la gestión de políticas públicas y demás acciones de carácter público, estarán en condiciones de gestionar el desarrollo socioeconómico local, de manera participativa y coordinada con los diferentes actores inmersos en sus ámbitos de acción. Asimismo, podrán asumir sin mayores dificultades las funciones y competencias provenientes como producto del proceso de descentralización del Estado. 
Nosotros hemos tenido la invitación para poder tener algunos cursos de capacitación. Cada ONG nos invita, y como no tenemos mucho conocimiento en cuestiones de gestión, entonces nosotros vamos participando en los talleres... Casi en la culminación de la gestión que tuvimos, creo que algunos hermanos u organizaciones han quedado satisfechos, yo creo que con eso ha tenido mucho que contribuir REMURPE a sus necesidades... No será tanto productivo pero si nos imbuimos de conocimientos. (Lucio Ccopa Mamani, Exalcalde del Distrito de Pichacani-Laraqueri, Puno).

Han habido talleres muy importantes de capacitación, un diplomado que hay últimamente sobre asociativismo y desarrollo económico, eso es un aporte importantísimo al país para el desarrollo económico productivo, generación de empleo, impulsar y promover que los municipios hagan un verdadero desarrollo económico en sus jurisdicciones (Nelson Mío, Alcalde del Distrito de Matanza y presidente de la Mancomunidad Municipal Vicus, Piura).

No obstante, a pesar del esfuerzo invaluable que realiza la REMURPE en torno al fortalecimiento de las capacidades de gestión de los gobiernos locales, quizá el talón de Aquiles de sus acciones se sitúe en que todo el programa de formación está dirigida a los actores institucionales - autoridades y funcionarios municipales ${ }^{-}$, quienes debido a la naturaleza y condiciones de sus cargos y puestos institucionales, por un lado, son poco perdurables, y por otro, no estarían traduciendo los conocimientos y aprendizajes adquiridos en la transformación de sus realidades locales, es decir, en el impulso del desarrollo socioeconómico local y en el bienestar social. Todo ello, además se debería a la no inclusión de los actores sociales locales en las acciones de formación y empoderamiento, o en todo caso a la inexistencia de un mecanismo o instrumento de seguimiento de las acciones y resultados en los propios ámbitos locales; aunque en algunas zonas se está impulsando redes de técnicos locales, quienes darían sostenibilidad a las acciones emprendidas y experiencias desarrolladas.

REMURPE se esfuerza bastante para apoyar a los gobiernos locales rurales, pero pienso que los alcaldes todavía no están entendiendo que es lo que quiere REMURPE, ahí lo que falta es trabajar con autoridades y población, y generar un proyecto político y técnico que efectivamente demuestre que es lo que quiere. El malo ahí no es REMURPE, sino las autoridades que cuando están capacitados y van al terreno no logran pasar la valla, es como si hubiera una barrera entre lo cotidiano y lo nuevo, y entonces lo nuevo no logra trascender lo cotidiano (Senon Choquehuanca, Coordinador de la Asociación SER en Puno). 
Entre nuestras acciones tenemos en marcha el programa de fortalecimiento de mujeres regidoras, ellas desarrollan acciones de liderazgo, asesoramiento y formación en sus áreas de influencia social y territorial, sólo que tenemos la dificultad de que cuando ellas ya se van, es decir, cuando terminan sus periodos de gestión, entonces se cambia de autoridades y se va perdiendo lo aprendido; sin embargo, hemos formado una red de técnicos, quienes se encargan de capacitar a los funcionarios técnicos nuevos de los municipios y otros interesados en el tema, esta experiencia es la que ha venido $y$ viene funcionando con éxito (Alexander Rojas, Secretario Técnico de la REMURPI Piura).

La gestión sostenible de los recursos naturales y promoción del desarrollo económico local, entendido como el uso, conservación y aprovechamiento racional de los recursos naturales en salvaguarda de la identidad y las necesidades básicas de las poblaciones locales donde se sitúan dichos recursos, tiene su sustento en el enfoque de desarrollo socioeconómico endógeno o etnodesarrollo; según el cual el desarrollo es el ejercicio de la capacidad social de un pueblo para construir su fututo, aprovechando las enseñanzas de su experiencia histórica y los recursos reales y potenciales de su cultura, de acuerdo con un proyecto que se defina según sus propios valores y aspiraciones (Binfil, 1995).

De acuerdo con lo anterior, mediante el asociativismo y la cooperación intermunicipal, los actores locales han impulsado iniciativas de desarrollo socioeconómico local aprovechando sus recursos y potencialidades locales, con el apoyo financiero de entidades de cooperación internacional, donde ha incidido el rol promotor de la REMURPE. En algunas regiones, a través de las asociaciones y mancomunidades municipales se han impulsado experiencias interesantes de desarrollo socioeconómico local, donde los propios actores y agentes locales son los protagonistas del proceso. $Y$ este proceso se viabiliza en la medida que hay voluntad, dinamismo y liderazgo político de las autoridades locales, el apoyo técnico, y la participación de los actores sociales en dicho proceso; este es el caso de las experiencias desarrolladas en la zona norte del país y no así en el sur.

La Mancomunidad del Corredor Andino Central ha presentado iniciativas de proyectos que han sido aprobados, ya desde la gestión anterior, proyectos de equidad de género liderados por la ONG Flora Tristán de la cooperación española y que hoy tiene un proyecto en ejecución que se llama Justicia Climática y Mujer Rural, trabaja con 40 mujeres productoras de Piura, de nuestra mancomunidad, y 40 mujeres productoras del Cusco ( Esguar Rodríguez, Alcalde del Distrito de Santa Catalina y Presidente de la Mancomunidad del Corredor Andino Central, Piura). 
Ya el año pasado hicimos una obra con financiamiento de Ayuda en Acción para una planta seleccionadora de granos y menestras, para dar valor agregado a nuestros productos agropecuarios, que se ha instalado en mi Distrito, entonces ya hay algunos resultados (Nelson Mío,Alcalde del Distrito de Matanza y Presidente de la Mancomunidad Municipal Vicus, Piura).

Durante mi participación en REMURPE no hemos tenido un beneficio concreto en términos materiales, falta trabajar eso a nivel de municipalidades, yo creo que REMURPE debe proyectarse más allá, buscar financiamiento para proyectos, a eso no hemos llegado, mas la REMURPE ha sido una instancia para poder reflexionar sobre procesos digamos coyunturas económicas, normativas nacionales, pero lo que si no se trabajó en Puno es la búsqueda de financiamiento, no se ha conseguido absolutamente nada (Iván Flores, ex-alcalde del Distrito de Acora, Puno).

\section{INSTRUMENTOS DE GESTIÓN INSTITUCIONAL}

Dado el estatus jurídico privado de la REMURPE, por un lado, y su composición por actores públicos locales, por otro, la gestión institucional está influenciada significativamente por el enfoque de la "nueva gestión pública", enfoque que está basado en la búsqueda y el logro de resultados mediante la eficiencia y la eficacia, y a su vez mediante el uso y aplicación de la planificación estratégica y la medición de resultados. Estos valores e instrumentos de gestión son propios de la economía de mercado. De esta manera, tanto la matriz de planificación como el flujograma del proceso de planificación, monitoreo y evaluación de la REMURPE, reflejan en buena medida el uso y aplicación de aquellos valores e instrumentos de gestión. Sin embargo, la filosofía institucional de la Red hace que en el proceso haya una complementariedad entre estos elementos de la nueva gestión pública y los principios comunitarios de organización rural-andina que dieron origen a la Red, cuyos miembros o actores participantes en gran medida provienen de estos ámbitos en la actualidad.

Como parte de la reproducción, desarrollo e innovación de aquellos principios comunitarios, y dado que el desarrollo de capacidades de gestión de los actores municipales es uno de los ejes centrales de las acciones de la Red, a lo largo de los últimos diez años, se han implementado metodologías e instrumentos de gestión del conocimiento basados en la cooperación y la reciprocidad andina, tales como el "sistema de inter-aprendizaje”, cuyo sustento básico es el “municipio-escuela”. Según REMURPE (2007a), el Municipio Escuela se define como una experiencia alternativa de aprendizaje, porque promueve una estrategia independiente de los sistemas formales y/o estructurados de capacitación municipal, el principal capital docente 
lo constituye la propia experiencia de los municipios asociados a REMURPE. En el mundo rural, donde principalmente opera REMURPE no existe separación entre aprender y vivir la experiencia in situ. El Municipio Escuela recoge esta característica del mundo andino para construir sobre esa base su estrategia metodológica de capacitación vivencial en respuesta a las necesidades de los municipios rurales.

Metodologías e instrumentos de gestión similares a lo expuesto se han desarrollado e innovado a partir de principios y experiencias comunitarias que dan sustento a la Red, las que sin embargo, con el transcurrir del tiempo se estarían viendo opacadas, si no dominadas, por los valores e instrumentos de gestión propugnadas por la economía de mercado; lo que sin duda vendría a subsumir el sustento y la filosofía fundacional de la Red.

Yo creo que al principio el trabajo comunitario de los municipios rurales ha sido importante, ahora yo creo que cada vez más se está diluyendo, aunque estamos en un ciclo donde el tema de identidad está floreciendo, pero yo sigo pensando que la penetración de otros patrones culturales en las sociedades andinas como que diluyen el tema colectivo y solidario... Entonces, si bien en la base todo esto es beneficioso, pero también se cruza con otros procesos que han ido diluyendo este aspecto tan rico de la cultura peruana, la cultura andina, de la reciprocidad, del compromiso colectivo y el ayni, los patrones individuales también han hecho mella de todo esto, estamos en este juego. Así, entre las dos culturas te generan un espacio así como medio de limbo (Eduardo Barzola, Secretario Técnico Nacional de la REMURPE).

Ante este panorama, en aras de la preservación e innovación justa de los principios y valores comunitarios de la cultura andina que dio sustento a la Red, es relevante que la gestión de las acciones institucionales no pierda de vista su filosofía fundacional, esto a pesar de que los principios y valores de la economía de mercado hayan ganado terreno en el proceso de gestión y desarrollo de la organización. Porque, como sostienen Arellano y Cabrero (2005), en la medida que la eficiencia sea el impulsor de las organizaciones públicas y la meritocracia orientado a resultados sean los principales valores organizacionales, se estarían proporcionando todos los elementos necesarios para crear un gobierno bueno y racional $y$, por tanto, moral. Dicho de otra manera, en la medida que diseñemos buenas instituciones y organizaciones que sigan las reglas del mercado, será racional actuar moralmente y la captura será evitada, porque está en los propios intereses egoístas de los actores el evitar ser capturado. Este argumento se sustenta en la idea de que "los seres humanos deben ser dueños de sí mismos (self-ownership) como el único medio para crear una sociedad justa". Sin embargo, esta idea ha demostrado y está demostrando ser insostenible e infructuoso en el tiempo. 


\section{PROCESO DETOMA DE DECISIONESY RELACIONES DE PODER: CONFLICTO Y COOPERACIÓN}

El modelo de toma de decisiones adoptado por la Red consiste en un modelo híbrido, a saber el "modelo de planificación racional-estratégica" propuesto por Quispe (20 I I), o el "modelo de exploración combinada" de Etzioni (I996). Según el primer modelo el proceso de toma de cisiones en torno a la adopción de políticas públicas se desarrolla multilateralmente, que es lo mismo decir de manera participativa; de ahí que éste modelo incluso puede ser asumido como el "modelo de planificación racional-participativa", buscando de esa manera la complementariedad entre los dos modelos clásicos de toma de decisiones: "actor racional" y "racionalidad limitada o incremental". En esta orientación es que, precisamente, se presenta el "modelo de exploración combinada", donde se toma en consideración de manera complementaria, tanto los planteamientos selectivos del incrementalismo como el maximalismo del actor racional, considerando el elemento de la complejidad en el proceso de las políticas.

Ahora bien, en la medida que se concibe a la REMURPE como una red de políticas públicas locales, desde su origen y hasta la actualidad ha tenido su sustento en el enfoque participativo para su configuración institucional y para la adopción de decisiones de políticas, donde dependiendo de la naturaleza de la política pública participan diversos actores públicos ${ }^{-}$diferentes instancias de los gobiernos locales, gobiernos regionales y gobierno nacional ${ }^{-}$, privados ${ }^{-}$ONGs y agencias de cooperación internacional ${ }^{-}$y sociales ${ }^{-}$CCP, CNA y algunas organizaciones de la sociedad civil ${ }^{-}$con información, formación, intereses y preferencias diferentes, las que se someten al proceso de negociación en diversos espacios establecidos tanto formal e informalmente. De esta manera, podemos sostener que de acuerdo con el modelo adoptado para la toma de decisiones expuesto más arriba, la Red ha implementado y desarrollado un enfoque "democrático-participativo y centralizado" en el proceso de toma de decisiones. Este enfoque responde a su estructura de organización y a los principios y valores democráticos y participativos de los actores integrantes.

Por su cobertura de un número significativo de municipalidades a nivel nacional -individualmente $\circ$ a través de mancomunidades, asociaciones y redes regionales-, la Red establece mecanismos graduales o jerarquizados de participación de los actores municipales asociados y no asociados, directivos y técnicos en el proceso de toma de decisiones, en la definición de la agenda de actuaciones y en la construcción del sistema de planificación. Lógicamente y en todos los sentidos, la tendencia del proceso es hacia la centralización y concentración del mismo en los actores estratégicos y claves de la Red. Así, desde la perspectiva de Marsh y Rodes citado por Evans (1998), la REMURPE como una red de políticas públicas no es exclusiva ni es exhaustiva. No es exclusiva, porque dentro de ella coexisten otras redes específicas o comunidades de políticas configuradas, de un lado, por asociaciones, mancomunidades y redes regionales de municipalidades; y de otro lado, por temas específicos relacionados con las áreas estratégicas de acción de 
la Red. No es exhaustiva, porque hay redes centrales y periféricas. La red central estaría configurada por aquellos actores estratégicos y claves de la organización que constituyen el ápice estratégico: la junta directiva nacional y la secretaría técnica nacional.Y las redes periféricas estarían configuradas por las asociaciones, mancomunidades y redes regionales de municipalidades.

Nosotros como secretaría ejecutiva nos relacionamos a nivel nacional, como una red tenemos redes regionales, algunas con mayor fuerza que otras, por ejemplo en Cusco, Piura, Puno, Cajamarca se podrían decir que son redes regionales de REMURPE, pero también nos relacionamos con otras regiones donde no hay redes de municipalidades, con asociaciones y mancomunidades municipales, por ejemplo con la AMRESAM en San Martin, la AMUZCEH en Huancavelica. Donde no hay red regional hay otro nivel de ramificación, y estos a su vez son autónomos porque tienen sus propios equipos técnicos, con quienes nos relacionamos para implementar acciones en las regiones.

Los directivos juegan un rol más político, son los que definen las agendas nacionales con sus socios en asamblea, por eso siempre se invita a las asociaciones que son socios. Cada red y asociación regional tiene sus propios asociados, estos vienen a ser automáticamente socios de REMURPE; mayormente en nuestras asambleas ampliadas participan los presidentes de redes regionales o mancomunidades, pero cuando es para junta directiva sólo quienes son afiliados a REMURPE.

(Yolanda Collatón, Secretaria Técnica del área DEL de la REMURPE)

En la medida que los diferentes actores integrantes de la Red disponen de recursos o capacidades diferentes, esto condiciona la dinámica de las relaciones de poder entre ellos, tanto al interior como al exterior de la organización. Ahora bien, si el poder radica en la posesión de dichos recursos o capacidades, desde la perspectiva del Análisis de Redes Sociales, el comportamiento de los actores, ya sean individuales o colectivos, se interpreta a la luz de sus posiciones variables dentro de la estructura social, posiciones que se dan como producto del acceso a recursos sociales (Lozares, 1996). Dichos recursos sociales se derivan de las redes de relaciones sociales desarrolladas por individuos y colectivos. Además, en términos de Lomnitz (2002), el comportamiento político de los actores se analiza desde la perspectiva de la cultura política, que consiste en la estructura de las redes sociales que tienen relación con el poder. La estructura y función de las redes sociales depende de la dirección en la que se dan los intercambios, de lo que se intercambia, y de la articulación que se da entre las redes. Los intercambios se dan simétrica y asimétricamente, los que van conformando redes horizontales y verticales, respectivamente. Estas redes se van articulando entre sí, conformando el tejido social. 
Los actores participantes en la REMURPE a nivel de las redes regionales y a nivel nacional tienen características y condiciones muy diversas, aunque tengan características similares por el aspecto de la ruralidad de los gobiernos locales. Esta característica heterogénea y variada de los gobiernos locales ha hecho que, en su mayoría, vean su participación en la REMURPE como un medio/estrategia de conseguir incrementar su presupuesto municipal a través de la cooperación nacional e internacional. En este sentido, algunos de los pequeños gobiernos locales han actuado, en la REMURPE, bajo una racionalidad instrumental, a quienes podríamos llamar pragmático-particularistas. De otra parte, habría existido un grupo de gobiernos locales más centrado y orientado en la articulación y cohesión institucional para reivindicar sus características y derechos de gobierno, a quienes llamaríamos reivindicativo-municipalistas. Finalmente, existiría un grupo de gobiernos locales o asociaciones municipales, cuyo propósito es desarrollar y fortalecer sus capacidades técnicas de gestión y representación política, quienes participarían en la REMURPE con el fin de responder apropiadamente a sus necesidades prácticas e intereses estratégicos desde un espacio organizativo e institucional, a quienes llamaríamos estratégico-visionarios.

Yo tengo esta idea, hay un sector de alcaldes y/o representantes que considera que la REMURPE es un actor gremial y un espacio de reivindicación para sus necesidades: municipios pobres y apuestan $100 \%$ por la red, siempre hay alcaldes que vienen de una formación política y un compromiso político de cambio, en el sur andino hay mucho de ellos, quienes forman parte de la directiva, estánWilbert Rozas, Carlos López,o Paucar. Un segundo sector que dicen que la REMURPE es una institución que me ayuda a estar cerca de las instituciones y autoridades, dicen que todas estas cosas que veo aquí las aprovecho.Y un tercer sector que dice proyectos, plata, se acercan porque van a conseguir fondos de la Unión Europea, junto con ITDG ahí si quieren inscribirse al toque. No podría yo cerrarlo a un solo sector, hay distintos tipos de comportamiento (Eduardo Barzola, Secretario Técnico Nacional de la REMURPE).

Todos los fundadores de la REMURPE y aquellos actores relacionados con su funcionamiento desde el inicio sostienen que la Red nació como un espacio de articulación e intercambio de recursos o capacidades: replicabilidad y generación de experiencias de gestión alternativa a nivel local y la reivindicación de los derechos e intereses de los gobiernos locales rurales. En este sentido, a lo largo de estos últimos diez años se ha construido redes de intercambio tanto de carácter simétrico como de carácter asimétrico, dando lugar a la configuración de relaciones de poder, relativamente, horizontal entre los gobiernos locales rurales y de pequeña escala: las mancomunidades, asociaciones y redes municipales, esto al interior de la $\operatorname{Red}^{63}$;

63 Las relaciones de poder "relativamente" horizontal entre los actores al interior de la Red, consiste en el trato más o menos igual entre los actores municipales que participan, ya sea individual o colectivamente, en la Red. 
asimismo, se ha configurado relaciones de poder vertical al exterior de la Red, esto en las acciones de incidencia en los procesos de adopción y formulación de políticas públicas a nivel regional/departamental y nacional. Estas redes de relaciones que se establecen entre los diferentes actores y a distintos niveles se explican por las pautas de interacción que guían a las organizaciones, pautas de interacción defendida por la "teoría sociológica-organizacional", a saber: la interdependencia y la cooperación. Sin embargo, en el proceso de interacción organizacional o entre los actores de la Red, tarde o temprano, se produce conflictos de preferencias e intereses como una condición necesaria e inevitable, sostenida por la "teoría del conflicto social".

En suma, en la medida que la REMURPE se desempeña como una red en cuyo interior interactúan redes específicas o comunidades de políticas públicas basada en relaciones de poder relativamente horizontal; $y$ además, como red interactúa con otros actores o redes del entorno meso y macro, basada en relaciones de poder vertical, que responde a la lógica de interacción de la jerarquía estatal, podemos sostener que existe una relación dialéctica tanto entre los actores dentro de la red como entre las diversas redes.

\section{DINÁMICA DE CONFIGURACIÓN DE LAS REDCIM}

La dinámica y lógica de configuración de las REDCIM que se han desarrollado a través de la REMURPE en el Perú ha sido variada y heterogénea, esta heterogeneidad es propia de los gobiernos locales rurales, quienes, en mayor medida, constituyen las REDCIM a nivel local y regional, y que a través de estas forman parte de la Red nacional.

Las REDCIM que se configuran al interior $y$ en torno a la REMURPE son de tres tipos básicos: asociaciones, mancomunidades y redes regionales de municipalidades. De acuerdo con las pautas analíticas planteadas por Cravacuore (2006), Díaz de Landa (2007) y Pírez (1998), podemos clasificar dichas REDCIM de la siguiente manera: primero, por el origen de las iniciativas de cooperación intermunicipal ya sea local o extralocal: voluntaria y consensuada, inducida y condicionada, impuesta y regulada, o formas mixtas. Segundo, por sus objetivos o fines que persiguen: fortalecimiento de capacidades de gestión y representación institucional, gestión compartida de servicios públicos municipales, y desarrollo territorial micro-regional o interregional. Tercero, por su cobertura territorial: iniciativas de cooperación intermunicipal de cobertura interdistrital, interprovincial, interregional e internacional. Cuarto, por su reconocimiento socio-institucional: bajo, mediano y alto grado de reconocimiento y legitimidad socio-institucional.

Si analizamos cada una de las REDCIM que integra la REMURPE, podríamos clasificar o tipificar, en función de sus características, en algunas de las modalidades de cooperación. Análisis que escapa de los propósitos de este trabajo. Sin embargo, lo que a groso modo podemos dar cuenta es de la tendencia que han tenido las REDCIM que participan de la REMURPE para tener una idea o representación clara 
de la lógica y dinámica de configuración de las mismas. La gran mayoría de estas REDCIM han tenido su origen por iniciativa voluntaria y consensuada de los propios actores municipales interdistritales e interprovinciales o en combinación entre ambas; la voluntad y el consenso entre estos actores se da en torno a objetivos y fines compartidos: el fortalecimiento de sus capacidades de gestión y representación institucional, $y$ el desarrollo territorial micro-regional o interregional. Mientras que su grado de reconocimiento y legitimidad socio-institucional es variado, fluctuando entre los tres grados: bajo, medio y alto, lo que se debería a la antigüedad y al grado de contribución en las acciones de desarrollo socioeconómico de sus ámbitos de referencia.

\section{Gráfico 4: Diagrama de Red de la REMURPE}

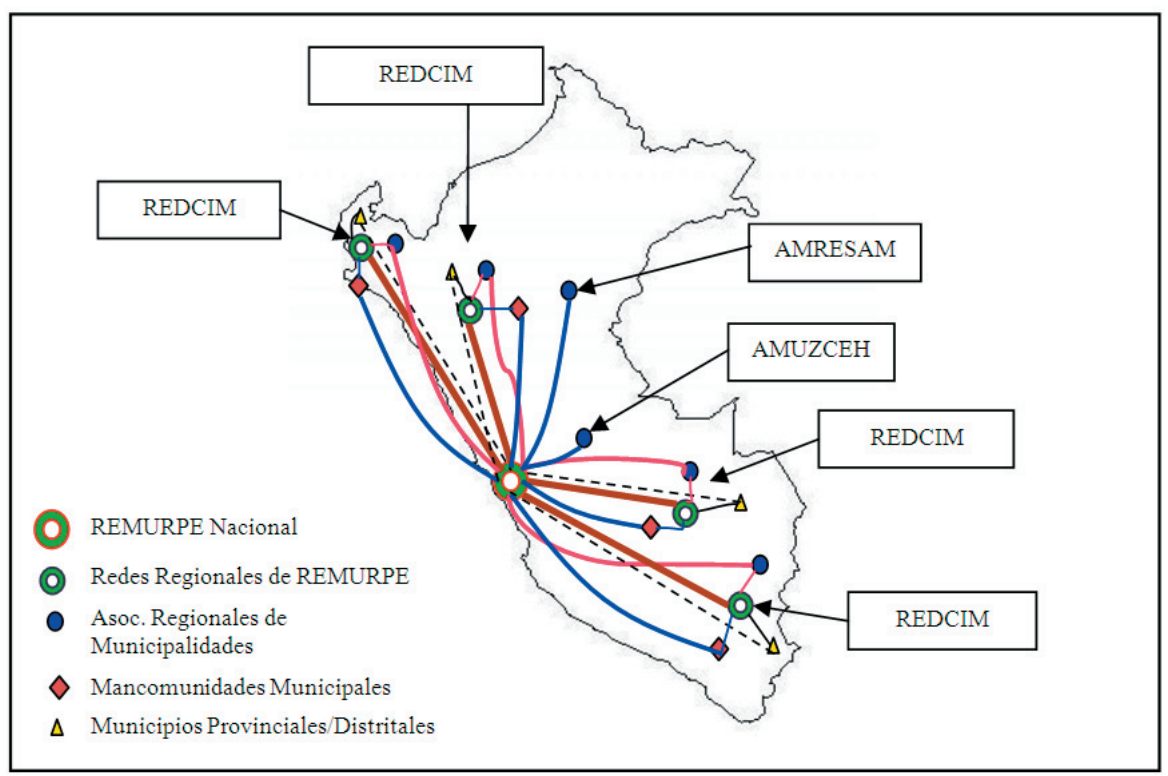

Fuente: Elaboración propia.

\section{CONSTRUCCIÓN E IMPLEMENTACIÓN DE UN MODELO DE GOBERNANZA LOCAL EN RED}

Dado el carácter deficitario de los sistemas democráticos en América Latina, donde en muchos países aún se mantiene el carácter patrimonialista del Estado, el modelo de gobierno está basado en patrones de relación vertical y jerárquico, donde las decisiones en torno a la adopción e implementación de políticas públicas se desarrollan de manera unilateral, incluso de manera autoritaria, $y$ en algunos casos con la participación de determinados grupos de interés, a pesar de la implementación formal de mecanismos de participación y concertación entre los diferentes actores gubernamentales, privados y sociales. Esta lógica de gobierno centralizado y 
jerárquico genera la ingobernabilidad del sistema político-democrático, modelo que aun se ha mantenido vigente en el Perú durante la última década. En este contexto, y para afrontar dicha situación es que los actores políticos locales han ideado la construcción e implementación de una alternativa de gestión gubernamental desde lo local, a través de la REMURPE, que sería definido como la construcción e implementación de un nuevo modelo de gobierno y gestión pública local basado en la articulación e intercambio de experiencias, recursos y capacidades entre los diferentes actores a diferentes niveles. Lo que en términos de Peters (2007), y Fernández y Mota (2009), sería concebido como el proceso de "gobernanza local en red", cuya lógica se sustenta en un proceso complejo mayor de "dirección y control". Los procesos de dirección y control de las decisiones y acciones de desarrollo socioeconómico de las sociedades locales implican la articulación e interacción entre los diferentes actores a nivel local, regional/provincial, nacional e internacional.

Con la construcción e implementación de la gobernanza local en red, lo que se busca y propone es reformar las relaciones entre Estado y sociedad, donde, por un lado, el Estado encarnado en los diferentes niveles de gobierno juegue el rol de dirección o liderazgo político en las decisiones y acciones de desarrollo y bienestar social, y por otro lado, la sociedad juegue el rol de control y vigilancia social en todo ese proceso. En este sentido, la gobernanza local en red no significa sólo la inclusión de actores público-estatales y privado-empresariales en el proceso de las políticas, sino también de los actores sociales organizados, distinguiéndose con ello de los modelos de gobernanza local europea y anglosajona.

Los mecanismos o espacios clave, utilizados por la REMURPE, para la construcción e implementación de la gobernanza local en red han girado, principalmente, en torno a la Conferencia Anual de Municipalidades Rurales (CAMUR) y las diversas acciones de incidencia en la adopción de políticas públicas locales. La CAMUR es el espacio cumbre de la Red que congrega a diferentes actores públicos, privados y sociales; se difunden las demandas, intereses y propuestas de los actores locales; espacio donde interactúan y concertan los diversos actores; $y$ se define en buena medida la agenda de actuaciones de la Red.

La actividad de mayor impacto para la REMURPE siempre ha sido la CAMUR, porque esta es la actividad que refleja todo lo que hemos hecho en todo el año y en todas las líneas de trabajo...... Te digo, porque tu juntas a todos, tienes en primera instancia a los representantes que toman decisiones a nivel nacional, tienes ahí las experiencias municipales que has estado apoyando en sus diferentes líneas y las muestras, damos propuestas desde abajo, mostrando lo que se ha logrado para que la gente de arriba conozca qué se está haciendo en los municipios, tienes a los directivos que tienen un rol muy protagónico porque son los que están sentados ahí proponiendo, pero al final de la CAMUR se define una agenda muy concertada y 
participativa. Imagínate a 500 personas en la CAMUR definiendo y revisando una agenda, $y$ es firmada por todas las autoridades y esa es la agenda guía de nuestro trabajo institucional anual.

Más allá de ser un evento que congrega a más de 500 personas, la idea ahí es articular con los otros niveles de gobierno, socializar y desarrollar la agenda de interés anual, se define la temática a desarrollar este año, y a la vez sirve para poner una agenda de incidencia dependiendo a qué organismos se tenga que incidir (Yolanda Collatón, Secretaria Técnica del área DEL de la REMURPE).

De esta manera, si bien el proceso de gobernanza local en red tiene su punto de inflexión en la CAMUR, sin embargo, se construye e implementa en los procesos de incidencia, adopción e implementación de las políticas públicas locales como producto de la interacción entre los diferentes actores gubernamentales, el sector privado y la sociedad civil. En la medida que las acciones de incidencia están dirigidas, en función a temáticas diversas, hacia diversos organismos públicos de diferentes niveles de gobierno, y por el modelo jerárquico y centralizado de gestión gubernamental implementado en el país, las acciones de incidencia están dirigidas en mayor medida hacia los organismos del gobierno nacional. Esta propuesta de gobernanza local en red desarrollada por la REMURPE, a través de acciones de incidencia en el proceso de las políticas y la CAMUR, se presenta como un modelo complementario/alternativo a la vigente que, tanto en el pasado como en el presente, ha socavado y socaba las necesidades, demandas e intereses de las sociedades locales, y que además es inapropiado para afrontar la creciente complejidad sociopolítica, económica y cultural que vive la sociedad.

\section{CONCLUSIONES}

La REMURPE surge como respuesta a la reconfiguración de los actores locales y la crisis estructural del sistema político producido durante la década del noventa en el país, y dada las características de los actores impulsores se ha generado un modelo organizativo de carácter participativo y relativamente horizontal y centralizado, cuya peculiaridad destacable radica en que la gestión organizativa cuenta con una claridad en la distinción y complementariedad de las funciones y competencias entre los actores participantes e integrantes en la gestión técnica, y en la dirección o liderazgo político.

El proceso de toma de decisiones está basado en el modelo de "planificación racional-participativa" y en el enfoque "democrático-participativo y centralizado", todo ello en la medida que la REMURPE es concebida como una red de políticas públicas locales. Además, concebida como tal, se constata que la Red no es exclusiva ni es exhaustiva. No es exclusiva, porque dentro de ella coexisten otras redes específicas o comunidades de políticas.Y no es exhaustiva, porque cuenta con 
redes centrales y periféricas. De esta manera, se desarrollan relaciones de poder horizontal (cooperación) y vertical (conflicto) al interior y al exterior de la Red, respectivamente. Esto a su vez, da lugar a la existencia de una relación dialéctica tanto entre los actores dentro de la red como entre las diversas redes.

El desarrollo de las acciones en cada una de las áreas ha dado lugar al impulso de un modelo de "gobernanza local en red" como un modelo complementario/ alternativo a la vigente relación vertical entre Estado y sociedad; configurándose para ello sistemas de interacción entre actores de diferentes niveles de gobierno en el proceso de gestión de las políticas públicas locales, lideradas por los gobiernos locales. Sin embargo, en dicho proceso habría primado el uso de instrumentos basados en los valores de la economía de mercado, sobreponiéndose a los valores andinos que fue el sustento de la Red. Esta racionalidad instrumental se manifiesta en el comportamiento de los actores de la Red.

\section{BIBLIOGRAFÍA}

Arellano,D.y Cabrero,E.(2005) La nueva gestión pública y su teoría de la organización: ¿Son argumentos antiliberales? Justicia y equidad en el debate organizacional público. En Gestión y Política Pública. XIV(3), 599-6I8.

Bonfil, G. (1995) Etnodesarrollo:sus premisas jurídicas, políticas y de organización. En Obras Escogidas de Guillermo Bonfil Batalla. (p.p. 464-480). México: INAH/INI.

Claros, R. (2009) Balance y perspectivas del asociativismo municipal en el Perú. Actualidad Gubernamental, XIV(9), I-4.

Cravacuore,D.(2006)Análisis del asociativismo intermunicipal enArgentina. En Medio Ambiente y Urbanización. Año 22(64), 3-16.

Etzioni, A. (1996) La Exploración Combinada: Un tercer enfoque para la toma de decisiones. En L.Aguilar (ed.) La Hechura de las Políticas. México: Porrúa.

Evans, M. (1998) Análisis de redes de políticas públicas: una perspectiva británica. Gestión y Política Pública. II(2), 229-266.

Fernández,M.y Mota,F.(2009) Gobernanza multinivel en Europa.UnaAproximación desde el caso andaluz. Sevilla: Fundación Centro de Estudios Andaluces.

Klijn, E. (1998) Policy Networks: An Overview. En Kickert, W. J. M. y Koppenjan, J.F. (eds.) Managing Complex Networks. London: SAGE.

Lomnitz, L. A. (2002) Redes sociales y partidos políticos en Chile. Revista hispana para

el análisis de redes sociales, 3(2). http://revista-rdes.rediris.es

Lozares, C. (1996) La teoría de redes sociales. Papers 48, (p.p. 103-126). Barcelona: Universitat Autònoma de Barcelona.

Navarro, C. (2004) Democracia local y gobernanza multi-nivel. IX Congreso Internacional del CLAD sobre la Reforma del Estado y de la Administración Pública, Madrid, 2-5 Noviembre. 
Peters, B. G. (2007) The Meta-Governance of policy networks: steering at a distance, but still steering Estudio/Working Paper 78. Madrid: UAM.

Quispe, E. (20II) Comportamiento y liderazgo político local en el Perú. Revista Iberoamericana de Estudios Municipales. Año II(3), I5I-I72.

Quispe, E. (2003) Condicionantes de la participación y articulación entre los actores en los espacios de concertación para el desarrollo local. Experiencias de concertación en Moho y Carhuaz. Tesis de Maestría no publicada. Escuela de Graduados, PUCP, Lima.

REMURPE (20I0) Memoria institucional. Gestión 2003-20I0, Lima.

REMURPE (2007a) Municipio Escuela. Manual del Facilitador. Lima.

REMURPE (2007b) Plan de desarrollo institucional PDI 2007-20 I0. Lima.

Remy, M. I. (2005) Los gobiernos locales en el Perú: entre el entusiasmo democrático y el deterioro de la representación política. En V.Vich (ed.) El Estado está de vuelta: desigualdad, diversidad y democracia. Lima: IEP.

Salcedo, E. (2008) Cooperación intermunicipal: Experiencias de Asociación Municipal de la Red de Municipalidades Rurales del Perú - REMURPE. Informe de sistematización, Lima.

Pírez, P. (1998) Cooperación intermunicipal en el marco de la integración regional. Foro Intermunicipal Buenos Aires sin Fronteras. Buenos Aires, 27-29 Abril.

Díaz de Landa, M. (2007) Las relaciones intergubernamentales desde los gobiernos locales. En D. Cravacuore y R. Israel (coords.) Procesos políticos comparados en los municipios de Argentina y Chile (1990-2005). Buenos Aires: Universidad Nacional de Quilmes y Universidad Autónoma de Chile. 